\title{
Diferentes concentrações do inóculo de Cercospora sojina na intensidade da mancha foliar "olho-de-rã" em soja
}

\author{
Juliane Nicolodi Camera ${ }^{1,2}$, Carolina Cardoso Deuner ${ }^{1}$, Erlei Melo Reis ${ }^{1}$
}

\author{
${ }^{1}$ Universidade de Passo Fundo, Campus I, Bairro São José - BR 285 - KM 171, Caixa Postal 611, Passo Fundo, RS, Brasil. CEP $99052-900$. \\ ${ }^{2}$ Parte da dissertação de mestrado. \\ Autor para correspondência: Carolina Cardoso Deuner (carolinadeuner@upf.br) \\ Data de chegada: 24/04/2012. Aceito para publicação em: 23/04/2012.
}

1813

\section{RESUMO}

Camera, J.N.; Deuner, C.C.; Reis, E.M. Diferentes concentrações do inóculo de Cercospora sojina na intensidade da mancha foliar “olho-derã" em soja. Summa Phytopathologica, v.38, n.3, p.235-238, 2012.

A mancha foliar "olho-de-rã", cujo agente causal é o fungo
Cercospora sojina, causa grandes perdas no cultivo da soja,
principalmente na Argentina. Em experimento conduzido em
aboratório e câmara climatizada, objetivou-se verificar o efeito
de diferentes concentrações do inóculo de C. sojina na intensidade
a mancha foliar "olho-de-rã" em folíolos de soja. As
concentrações de conídios utilizadas foram de $10 \times 10^{3}, 20 \times 10^{3}$,
$30 \times 10^{3}, 40 \times 10^{3}, 50 \times 10^{3}$ e $60 \times 10^{3}$ conídios. $\mathrm{mL}^{-1}$, com e sem espalhante. Após a inoculação dos conídios por aspersão sobre os folíolos de soja, as plantas foram mantidas com molhamento foliar de 48 horas. Decorrido este período, as plantas permaneceram em câmara climatizada, em temperatura de $25^{\circ} \mathrm{C}$ por 15 dias. Avaliouse a severidade, número e diâmetro de lesões. A concentração de 35.000 conídios. $\mathrm{mL}^{-1}$ com espalhante gerou intensidade de doença que possibilita a quantificação rápida e precisa da doença, podendo ser utilizada em futuros trabalhos de pesquisa.

Palavras-chave adicionais: Espalhante, conídios, severidade, Glycine max.

\section{ABSTRACT}

Camera, J.N.; Deuner, C.C.; Reis, E.M. Different concentrations of Cercospora sojina inoculum on the intensity of frogeye leaf spot in soybeans. Summa Phytopathologica, v.38, n.3, p.235-238, 2012.

Frogeye leaf spot, the causative agent of which is the fungus Cercospora sojina, causes great losses to soybean crops, primarily in Argentina. The experiment, conducted in laboratory and acclimatization chamber, aimed to check the effect of different concentrations of inoculum of $C$. sojina on the intensity of Frogeye leaf spot in soybean leaflets. The used concentrations of conidia were $10 \times 10^{3}, 20 \times 10^{3}, 30 \times 1040 \times 10^{3}, 50 \times 10^{3}$ and $60 \times 10^{3}$ conidia. $\mathrm{mL}^{-1}$, with and without the presence of a spreader. After the inoculation of conidia by spraying on soybean leaflets, plants were maintained under 48-hour leaf wetness. After this period, the plants remained in an acclimatization chamber at $25{ }^{\circ} \mathrm{C}$ for 15 days. The severity, number and diameter of injuries were evaluated. The concentration of 35,000 conidia. $\mathrm{mL}^{-1}$ with the presence of the spreader generated a disease intensity that enables the rapid and accurate quantification of the disease and can be used in future research.

Additional keywords: Spreader, conidia, severity, Glycine max.

A soja [Glycine max (L.) Merr.] é uma leguminosa com grão rico em proteínas, cultivado como alimento, tanto para humanos, quanto para animais. É importante na alimentação graças às suas características nutricionais (6). Essa cultura é uma das leguminosas mais cultivadas no país, da germinação até a colheita, a cultura é submetida a contínuos e variados estresses de natureza biótica e abiótica de diferentes intensidades (2). Destacam-se os fatores de natureza biótica como, nematoides, vírus, bactérias e por fim, os fungos (10). Dentre os fungos que atacam a cultura da soja está Cercospora sojina Hara, agente causal da mancha foliar "olho-derã”.

Em fitopatologia pratica-se rotineiramente inúmeros trabalhos com inoculação artificial de fungos, visando reproduzir os sintomas da doença. Nestes trabalhos com inoculação artificial é necessária a determinação da melhor concentração de inóculo e, que leve a resultados reproduzíveis (8). Muitos trabalhos já foram desenvolvidos com a finalidade de determinar a melhor concentração de inóculo e demonstraram resultados significativos com outros patossistemas (4, $5,8)$.

Diferentes intensidades da doença podem ser geradas com diferentes temperaturas, distintas concentrações de inóculo, diferentes durações de período de molhamento foliar, variação da agressividade ou virulência do fungo e reação de cultivares $(12,15)$.

Devido à falta de informações sobre a concentração do inóculo de C. sojina capaz de causar infecção na cultura da soja, esse trabalho teve como objetivo verificar o efeito de diferentes concentrações do inóculo C. sojina com e sem espalhante sobre a intensidade da mancha foliar "olho-de-rã" em folíolos de soja do cultivar BMX Magna. 
O experimento foi conduzido no Laboratório de Fitopatologia e em câmara climatizada, na Faculdade de Agronomia e Medicina Veterinária da Universidade de Passo Fundo (UPF) - RS, durante o período de agosto a novembro de 2010.

O presente trabalho foi composto de sete tratamentos, utilizandose as seguintes concentrações de inóculo $\left(0,10 \times 10^{3}, 20 \times 10^{3}, 30 \times 10^{3}\right.$, $40 \times 10^{3}, 50 \times 10^{3}$ e $60 \times 10^{3}$ conídios. $\mathrm{mL}^{-1}$ ) com e sem espalhante [duas gotas por litro de Tween 20 (polioxietilenosorbitano)]. As inoculações foram realizadas quando as plantas encontravam-se em estádio V4 terceira folha trifoliada completamente desenvolvida (7). Utilizou-se o delineamento experimental interiamente casualizado com cinco repetições, com as unidades experimentais constituídas de um copo de plástico com duas plantas.

As plantas de soja, do cultivar suscetível BMX Magna foram cultivadas em copos plásticos de $300 \mathrm{~mL}$, utilizando-se como substrato $2,0 \mathrm{~kg}$ de solo hortado. Utilizou-se duas plantas por copo, sendo estes mantidos em câmara climatizada com temperatura de $25{ }^{\circ} \mathrm{C}$ e com fotoperíodo de 12 horas.

O inóculo de $C$. sojina raça 25 , utilizado nesse trabalho foi fornecido pela Embrapa Soja, e preservado na micoteca do Laboratório de Fitopatologia da Universidade de Passo Fundo.

Para iniciar o trabalho, fragmentos de colônias de C. sojina preservado em tubos contendo BDA foram transferidos para placas de petri contendo meio de cultura extrato de tomate (11). Essas placas permaneceram em câmara de crescimento, a $25^{\circ} \mathrm{C}$ e com fotoperíodo de 12 horas durante 30 dias, até obter-se esporulação abundante. Posterior à esporulação do fungo, adicionou-se em cada placa de petri com colônias puras do fungo, $10 \mathrm{~mL}$ de água destilada e esterilizada com a finalidade de obter-se uma suspensão de conídios. Dessa suspensão foi pipetado $1 \mathrm{~mL}$ e em seguida colocado em placas de petri contendo ágar-água a $1 \%$, sendo essas incubadas a $25{ }^{\circ} \mathrm{C}$ com fotoperíodo de 12 horas por um período de 12 horas. Decorrido este tempo, observou-se a germinação dos conídios e procedeu-se o isolamento monospórico. Com o auxílio de uma espátula esterilizada foram cortados 10 cubos de ágar-água, sendo que em cada um deles havia somente um conídio germinado. Cada cubo foi transferido para uma placa de petri contendo meio de cultura extrato de tomate (11), sendo as mesmas incubadas a $25{ }^{\circ} \mathrm{C}$ com fotoperíodo de 12 horas durante 30 dias, até obter-se esporulação abundante. A partir das culturas puras obtidas pelo isolamento monospórico, preparou-se uma suspensão de conídios com água esterilizada e outra suspensão com água esterilizada e espalhante. A densidade de inóculo foi determinada contando-se o número de conídios em $0,01 \mathrm{~mL}$ em lâmina

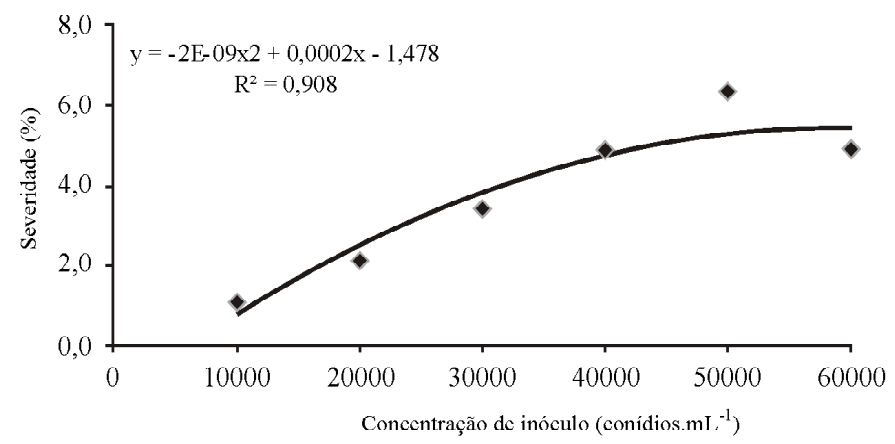

Figura 1 - Efeito da concentração de inóculo de Cercospora sojina sobre a severidade (\%) em folíolos de soja com espalhante no cultivar BMX Magna. Passo Fundo, RS. 2011. de vidro no microscópio. A partir da maior concentração $60 \times 10^{3}$ conídios. $\mathrm{mL}^{-1}$, por diluições, obteve-se as concentrações de $50 \times 10^{3}$, $40 \times 10^{3}, 30 \times 10^{3}, 20 \times 10^{3}$ e $10 \times 10^{3}$ conídios. $\mathrm{mL}^{-1}$, sendo a testemunha pulverizada apenas com água.

As plantas de soja do cultivar BMX Magna foram inoculadas no estádio V4 - terceira folha trifoliada completamente desenvolvida (7), com as diferentes concentrações de inóculo utilizando um aspersor manual, até ponto de escorrimento.

Após a inoculação, as plantas foram mantidas em câmara úmida com a utilização de caixas de acrílico, cobrindo-as por um período de 48 horas visando manter o molhamento foliar. As plantas permaneceram em câmara climatizada com temperatura constante de $25^{\circ} \mathrm{C}$ por 15 dias até o aparecimento dos sintomas da doença.

As avaliações das plantas de soja foram realizadas quinze dias após a inoculação. Foi verificado a intensidade da mancha foliar "olho-de-rã" nos três folíolos de soja do último trifólio totalmente expandido. Para isso, foi atribuído nota de severidade nos folíolos, contou-se o número de lesões por folíolo e mediu-se o diâmetro das lesões em função das diferentes concentrações do inóculo de $C$. sojina. Além disso, calculou-se pela fórmula de regressão, a melhor concentração do inóculo de $C$. sojina com e sem o uso de adjuvante.

Os resultados obtidos na intensidade de $C$. sojina, seja com ou sem espalhante, mostra que há relações entre a densidade de inóculo e a intensidade de doença (severidade, número e diâmetro de lesões por folíodos), sendo essas representadas por equações polinomiais quadrática (Figura 1 a 6). Os dados demonstram um aumento crescente da intensidade da $C$. sojina com o aumento da concentração de inóculo atingindo o nível mais alto (ponto máximo) no gráfico das variáveis avaliadas para, posteriormente, diminuir com o aumento da concentração.

No experimento onde testou-se as diferentes concentrações de inóculo de $C$. sojina com espalhante (Figura 1), a maior severidade da mancha foliar "olho-de-rã" foi obtida na concentração de 34.000 conídios. $\mathrm{mL}^{-1}$, sendo que esta foi calculada através da fórmula de regressão: $y=-4 \mathrm{E}-08 \mathrm{x}^{2}+0,0027 \mathrm{x}-26,16$, substitui-se o maior valor de y na concentração verificando-se que a melhor concentração foi de 34.000 conídios. $\mathrm{mL}^{-1}$.

Neste mesmo experimento, foram testadas diferentes concentrações do inóculo de C. sojina sem espalhante (Figura 2), a maior severidade da mancha foliar "olho-de-rã" foi obtida na concentração de 50.000 conídios. $\mathrm{mL}^{-1}$. Quando comparou-se com e sem espalhante verificou-se que a maior severidade da doença foi com a utilização do espalhante.

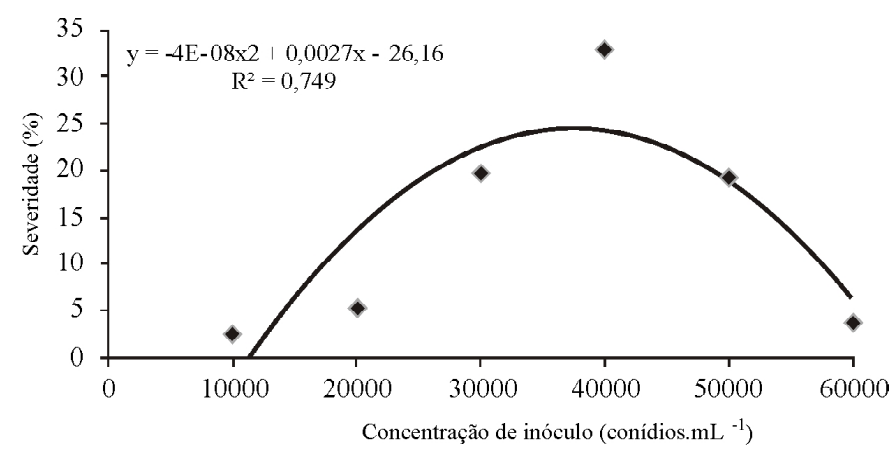

Figura 2 - Efeito da concentração de inóculo de Cercospora sojina sobre a severidade (\%) em folíolos de soja sem espalhante no cultivar BMX Magna. Passo Fundo, RS. 2011. 


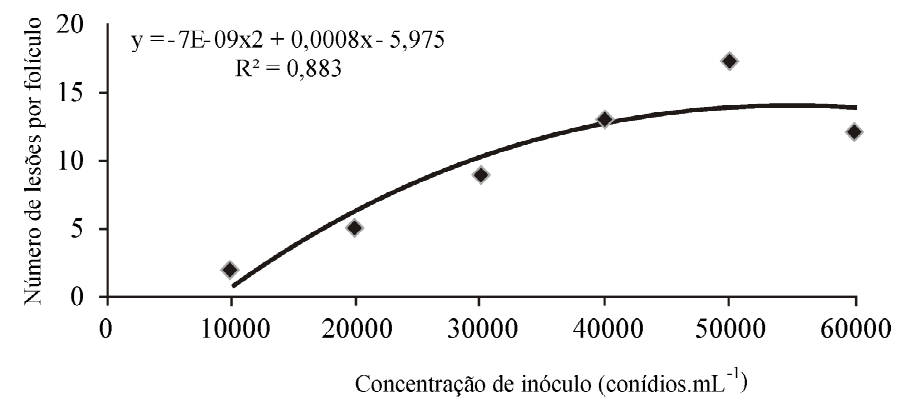

Figura 3 - Efeito da concentração de inóculo de Cercospora sojina sobre o número de lesões por folíolo com espalhante no cultivar BMX Magna. Passo Fundo, RS. 2011.

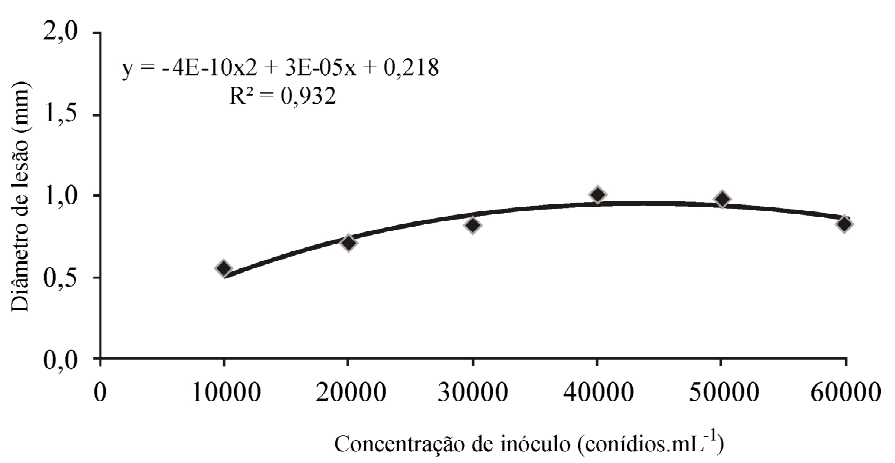

Figura 5 - Efeito da concentração de inóculo de Cercospora sojina sobre o diâmetro de lesões por folíolo com espalhante no cultivar BMX Magna. Passo Fundo, RS. 2011.

Em relação ao número de lesões por folíolo (Figura 3), o maior valor foi obtido na concentração de 36.000 conídios. $\mathrm{mL}^{-1}$, com espalhante, segundo a equação da regressão. Sem espalhante (Figura 4), o maior número de lesões foi obtido na concentração de 57.000 conídios. $\mathrm{mL}^{-1}$ de acordo com a equação da regressão.

Nos folíolos de soja, onde avaliou-se o diâmetro de lesões com espalhante (Figura 5), a concentração de 36.000 conídios. $\mathrm{mL}^{-1}$ apresentou o maior diâmetro pela equação da regressão. Porém, onde avaliou-se o diâmetro de lesões sem espalhante (Figura 6), a melhor concentração foi de 38.000 conídios. $\mathrm{mL}^{-1}$ demonstrada pela equação de regressão.

Dados semelhantes aos descritos neste trabalho foram obtidos por Barba et al. (1), em experimento realizado com Bipolaris sorokiniana (Sacc.), onde o mesmo testou diferentes concentrações de inóculo. Os dados deste autor demonstram um aumento crescente da intensidade da mancha marrom com o aumento da concentração de inóculo de $B$. sorokiniana, que após atingir o nível mais alto (ponto máximo) do número de manchas por folha e de severidade da doença, ocorreu à diminuição das mesmas. Esse aumento pode ser atribuído ao fato de que altas densidades de inóculo podem produzir um efeito antagônico na germinação dos esporos e/ou vários esporos podem participar de uma única infecção. As variáveis avaliadas da doença podem aumentar proporcionalmente com a concentração de esporos do patógeno até uma determinada concentração, acima da qual, dependendo do patossistema, pode ocorrer uma redução, causada, provavelmente, pela auto-inibição da germinação dos esporos, assim como pela existência de um número limitado de sítios de infecção (1). Não se encontrou

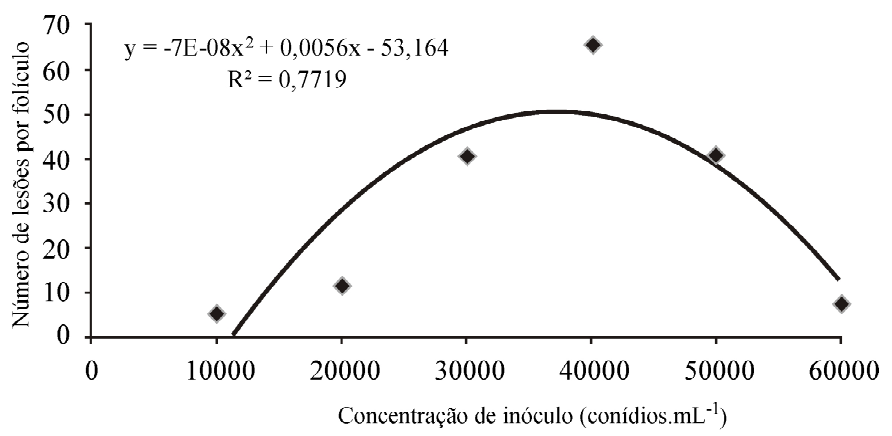

Figura 4 - Efeito da concentração de inóculo de Cercospora sojina sobre o número de lesões por folíolo sem espalhante no cultivar BMX Magna. Passo Fundo, RS. 2011.

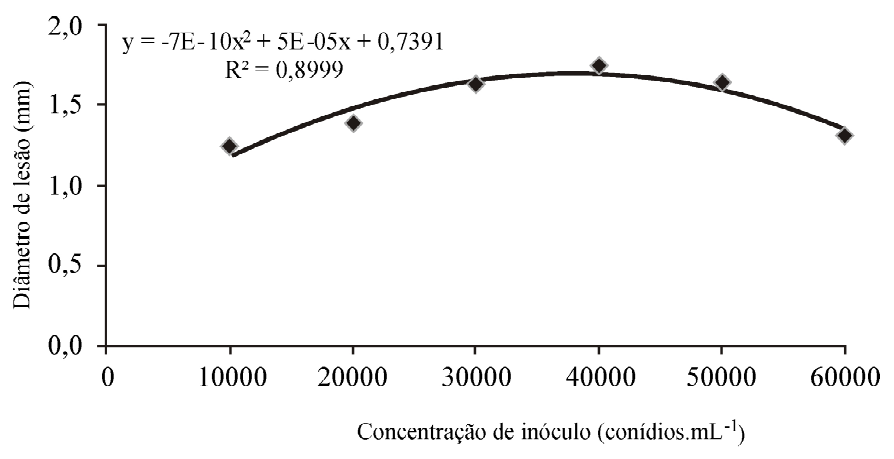

Figura 6 - Efeito da concentração de inóculo de Cercospora sojina sobre o diâmetro de lesões por folíolo sem espalhante no cultivar BMX Magna. Passo Fundo, RS. 2011.

informações específicas sobre este fenômeno a respeito do patossistema soja x C. sojina.

A média das concentrações obtidas nas variáveis avaliadas (severidade, número e diâmetro de lesões por folíolo) foi de 35.000 conídios. $\mathrm{mL}^{-1}$ com espalhante, e de 48.000 conídios. $\mathrm{mL}^{-1}$ sem espalhante.

A melhor concentração de inóculo de $C$. sojina encontrada neste trabalho corrobora com Carmona et al. (3), onde o mesmo utilizou a concentração de 30.000 conídios. $\mathrm{mL}^{-1}$ para a inoculação em seus experimentos com este fungo. Esta mesma concentração foi utilizada por Veiga (14) em seus trabalhos com reação de cultivares onde o autor utilizou as cultivares Bragg, Davis e Halle-7. Por outro lado, Gómez (9), conclui que a melhor concentração para inoculação de $C$. sojina é de 10.000 conídios. $\mathrm{mL}^{-1}$.

Em relação à utilização do espalhante, os resultados demonstraram que foi possível inocular menor quantidade de conídios. $\mathrm{mL}^{-1} \mathrm{e}$ obter maior intensidade da doença. Na maioria das vezes, a utilização de substâncias tenso-ativas ou espalhantes podem reduzir a tensão superficial das gotas pulverizadas causando o seu achatamento aumentando assim, a superfície de contato e prolongando a vida da gota (13).

\section{CONCLUSÕES}

Quanto ao efeito da densidade de inóculo na intensidade de $C$. sojina, o modelo de regressão segue uma tendência polinomial quadrática.

A concentração de 35.000 conídios. $\mathrm{mL}^{-1}$ com espalhante gera 
intensidade de doença que possibilita quantificações rápidas e precisas, podendo ser utilizada em futuros trabalhos de pesquisa.

A utilização do espalhante permite reduzir o número de conídios. $\mathrm{mL}^{-1}$ de $C$. sojina, resultando em maior intensidade da mancha foliar "olho-de-rã".

\section{REFERÊNCIAS BIBLIOGRÁFICAS}

1. Barba, J.T.; Reis, E.M.; Forcelini, C.A. Efeito do substrato na morfologia de conídios de Bipolaris sorokiniana e da densidade de inóculo na intensidade da mancha marrom em cevada. Fitopatologia Brasileira, Lavras v. 29, p. 5-10, 2004.

2. Bonato, E.R. Estresses em soja. Passo Fundo: Embrapa Trigo, 2000. 254p.

3. Carmona, M.; Scandiani, M.; Luque, A. Severe Outbreaks of Soybean Frogeye Leaf Spot Caused by Cercospora sojina in the Pampean Region, Argentina. Plant Diseases, Saint Paul, v. 93, n. 9, p. 966, 2009.

4. Carvalho, L.P.; Carvalho, J.M.F.C.; Lima, E.F.; Cavalcante, F.B. Influência da concentração de esporos da patogenicidade de Colletotrichum gossypii South var. cephalosporioides A. S. Costa e avaliação da resistência de cultivares e linhagens de algodoeiro herbáceo à ramulose. Fitopatologia Brasileira, Brasília, DF, v. 6, p. 395-402, 1981

5. Dalla Pria, M.; Amorim, L.; Bergamin Filho, A. Quantificação de componentes monociclíclos da mancha angular do feijoeiro. Fitopatologia Brasileira, Lavras, v. 28, p. 394-400, 2003.

6. Domagalski, J.M.; Kollipara, K.P.; Bates, A.H.; Brandon, D.L.; Friedman, M.; Hymowitz, T. Nulls for the major soybean Bow-
man-Birk protease inhibitor in the genus Glycine. Crop Science, Madison, v. 32, p. 1502-1505, 1992.

7. Fehr, W.R.; Caviness, C.E. Stages of soybean development. Ames: Iowa State University, 1977. 12p.

8. Fernandes, C.D.; Del Peloso, M.C.; Maffia, L.A.; Do Valle, F.X.R.; Zambolim, L. Influência da concentração de inóculo de Cercospora coffeicola e do período de molhamento foliar na intensidade da cercosporiose do cafeeiro. Fitopatologia Brasileira, Lavras, v. 16, p. 39-43, 1991.

9. Gómez, D.E. Cercospora sojina: produção de esporos, densidade de inóculo e reação de cultivares de soja. 2011. 94f. Dissertação (Mestrado em Agronomia) - Faculdade de Agronomia e Medicina Veterinária, Universidade de Passo Fundo, Passo Fundo.

10. Henning, A.A.; Godoy, C.V. Situação da ferrugem da soja no Brasil e no mundo. In.: Zambolim, L. Manejo integrado da ferrugem asiática da soja. Viçosa: Universidade Federal Viçosa, 2006. $140 \mathrm{p}$.

11. Hine, R.B.; Aragaki, M. Influence of soil temperature on a crown rot disease of parsley caused by Phytophthora parasitic. Phytopathology, Saint Paul, v. 53, p. 1113-1114, 1963.

12. Sutton, J.C. Predictive value of weather variables in the epidemiology and management of foliar diseases. Fitopatologia Brasileira, Brasília, DF, v. 13, p. 305-312, 1988.

13. Theisen, G.; Ruedell, J. Tecnologia de aplicação de herbicidas: teoria e prática. Passo Fundo: Aldeia Norte, 2004. 90p.

14. Veiga, P. Cercospora sojina Hara: obtenção de inóculo, inoculação e avaliação da resistência em soja (Glycine max (L.) Merrill). 1973. 32f. Dissertação (Mestrado em Agronomia) - Escola Superior de Agricultura Luiz de Queiroz, Piracicaba.

15. Zadoks, J.C.; SCHEIN, R.D. Epidemiology and plant disease management. New York: Oxford University Press, 1979. 427p. 